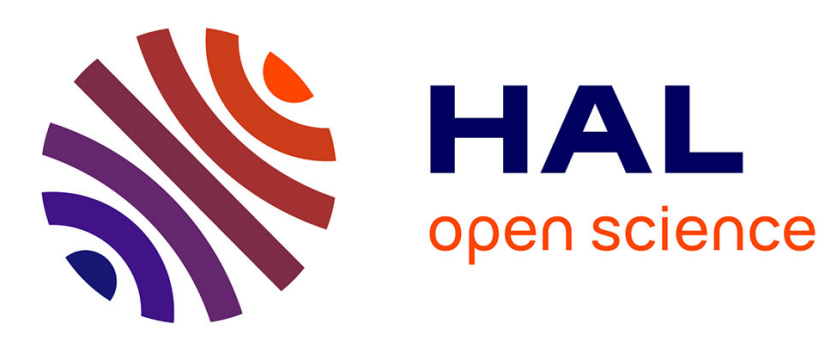

\title{
Smart Product Service System: Process Value Model in the Framework 3DCE
}

Thecle Alix, Grégory Zacharewicz

\section{To cite this version:}

Thecle Alix, Grégory Zacharewicz. Smart Product Service System: Process Value Model in the Framework 3DCE. 22nd Working Conference on Virtual Enterprises (PRO-VE 2021), Nov 2021, SaintEtienne, France. pp.494-505, 10.1007/978-3-030-85969-5_46 . emse-03346180

\section{HAL Id: emse-03346180 https://hal-emse.ccsd.cnrs.fr/emse-03346180}

Submitted on 25 Nov 2021

HAL is a multi-disciplinary open access archive for the deposit and dissemination of scientific research documents, whether they are published or not. The documents may come from teaching and research institutions in France or abroad, or from public or private research centers.
L'archive ouverte pluridisciplinaire HAL, est destinée au dépôt et à la diffusion de documents scientifiques de niveau recherche, publiés ou non, émanant des établissements d'enseignement et de recherche français ou étrangers, des laboratoires publics ou privés. 


\title{
Smart Product Service System: Process Value Model in the Framework 3DCE
}

\author{
Thecle Alix ${ }^{1}$ and Gregory Zacharewicz ${ }^{2}$ \\ ${ }^{1}$ Arts et Métiers Institute of Technology, I2M Bordeaux, F-33400 Talence, France \\ ${ }^{2}$ Laboratoire des Sciences des Risques (LSR) - IMT Mines Ales, 6 avenue de Clavières, 30319 \\ Alès Cedex, France, thecle.alix@ensam.eu
}

\begin{abstract}
The world industrial economy has turned into an economy of service over the past two decades. Evidence can be easily found, such as the shift of more and more manufacturers from traditional product-centered logic towards a service-centered logic. Transactional business models are evolving towards recurring revenue models, which raises questions about the new value proposition to be met. The addition of complementary services to the product to maintain, among other things, the performance of assets throughout the whole PSS life cycle presents both an opportunity and a complexity. To make this integration sustainable, we suggest operationalizing the PSS concept so that the value proposition is customer oriented, considering simultaneously the engineering of the offering, the processes, and the support network. We suggest developing scenarios of new value propositions based on service value process models. Our contribution will present a three-dimensional engineering framework as well as a service process value model.
\end{abstract}

Keywords: Process Value Model, Smart Product Service System, Three Dimensional Concurrent Engineering, Customer Orientation.

\section{Introduction}

Sustainable development has become a priority issue for manufacturing companies since: their commitment to a responsible policy aiming to avoid waste and resources overconsumption, rare and precious metals real criticality consideration, individual and collective awareness to reduce both one's own waste and environmental footprint, etc. Consequently, many challenges raise: which offer for which customer? how to do more with less? how to do better with less globally? how to adapt the offer to individual and collective usage which evolves over time? which business model for which product? how to eco-design? how to increase eco-circularity? etc.

Product Service Systems (PSS) defined as integrated solutions of services and goods based on the sale of a performance in use or a usage and not on the simple sale of goods" [1], [2], linked to modular eco-designed systems supported by specific business model, are a first step to reduce the renewable rate of products/service consumption in the society-rather measured at a micro economic level, and for specific sectors. Other strategies, such as the $10 \mathrm{R}$ strategies, are in progress to emphasize circular economy and intensify the use or expand the life of products or material, or recover products [3]. 
They allow preserving the value of the products. In general, product design needs to be thought in a comprehensive way, encompassing production processes, logistics systems, consumption patterns and lifestyles. The development of IOT and ICT plays in important role in the implementation of the $10 \mathrm{R}$ strategies, enabling the collection of customer behavioral data in real time and thus to renegotiate service level agreement based on real usage or to manage maintenance, etc. [4]. PSS, IOT and ICT association is currently implemented in what is called Smart PSS solutions. While promoting many advantages, Smart PSS still question on their effectiveness to satisfy the sustainable character and thus their design remains prevalent to promote sustainability $[4,5]$.

PSS design must encompass the compatibility and overlap of some components (subassemblies of the system) addressed to the consumer, and the processes supporting the design, manufacture, and provision of this offer. Both PSS design framework and smart PSS design framework have been proposed in the literature which mostly focus on the offering, sometimes on the coupling process, sometimes on the supporting network organization but rarely on these three dimensions simultaneously [6-8]. Modularity in PSS design is also exploited but only considering the offering dimension and not yet the support organization. To address such concerns, a three-dimensional PSS design framework is proposed in this paper based on a modular approach of products, services, and resources (industrial partners) or production resources used to support the offering production and delivery.

The following section reviews several useful notions and concepts to address the scope of our study. Section 3 reviews the design challenges that guided the key principles of the framework. The implementation and operationalization of the framework is presented in section 4 and 5. Finally, the paper ends with a conclusion that highlights the main points of the proposed framework and the directions for future work.

\section{Problem Statement}

The above-mentioned definition of PSS emphasises the sustainability of a solution developed to satisfy customers' requirements through a high value-added offering that favour companies' profit [1]. The concept of PSS has taken shape through several typologies linked to different coupling between the products and the services and to different business models. The satisfaction mentioned in the definition and primarily linked to the customers has been extended over the years to all stakeholders. The sustainability discussed initially based on environmental concerns has gradually integrated social and economic dimensions and is trying to consider the whole system lifecycle. The potential for added value has been opened to users and all stakeholders of these systems through the development of personalised e-services. All these evolutions, for which the core concepts are outlined hereafter, have a significant impact in the assumptions and structuring of the design framework we propose. 


\subsection{PSS and Smart Typologies and Representation}

The first recognized typology distinguishes three types of PSS: product-oriented PSS, use-oriented PSS and result-oriented PSS [9]. The difference between them concerns the offer dominant logic and the associated business model. This typology drawbacks are: first, the unrepresentative of the possibilities found in practice and, second that it is no more representative of the market evolution: customers' requirements and sustainable concerns. The classification proposed by Van Ostaeyen [10] distinguishes PSS based on: the performance orientation of the dominant revenue mechanism and the degree of integration between product and service elements. This typology question the coupling between the product and the service to determine if the service is supported by the product or added to the product or to the service expected by the product as a tangible support. Accordingly, the delivery mode can be constrained and the offering component proper existing conditions challenged. More recently Aas et al. [11] have proposed a typology with eight categories relevant in the digital era delineated in conjunction with the business models relates to the suppliers' ownership of delivered products degree, the smartness of the services provided degree and the performance orientation of contracts degree. This typology is more suitable with Smart PSS, the link to the business model is explicit, and the features of the service are considered. But the product and service coupling that can be a weakness regarding the sustainable concerns.

Smart services can be viewed as the combination of: (1) products: i.e., tangible supports for functional services inherent to the products, that cannot be sold independently; (2) support services: services linked to physical supports/functional services allowing to preserve its initial performance that cannot be sold separately; (3) additional services: pure service existing by themselves that can be sold separately. These services can be online (e-service) or offline. IoT can be used to help users or solution providers to better manage the product (e.g., maintenance) or to optimize its performance (e.g., energy management). It is also possible to imagine helping the system provider to design more reliable systems through, for example, feedback on incidents that have occurred during use. E-services as defined by Casati [12], are an "application accessible via the web, providing a set of functionalities to companies or individuals or viewed as a component provided by an organization to be assembled and reused in a distributed environment on the Internet". For their implementation, product support infrastructures are needed. These infrastructures may be other PSS or smart PSS solutions created to meet other primary needs. IOT + ICT can be used to propose either support or additional service.

Figure 1 summarizes the evolution from product to Smart PSS and the underlying typology.

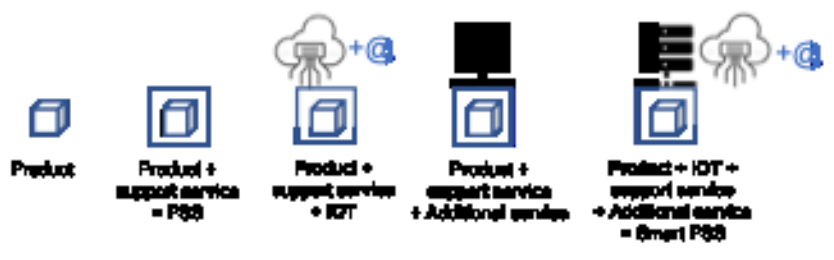

Fig. 1. From Product to Smart PSS. 


\subsection{Smart PSS as a Lever to Respond to Stakeholders" Sustainability Concerns}

Smart PSS solution are intended to be sustainable as their predecessors should be, either for customers and providers. Indeed, whatever the business model, customer usage needs satisfaction remains at the heart of the initial offer to which can be added services to ensure the tangible supports for functional services performance preservation if possible (e.g., maintenance). In the latter case, advantage may be: to anticipate failures before they occur and thus reduce the downtime or, to avoid excessive maintenance due to major failures in case he would own the solution. In the case where the owner of the solution is the provider, feedbacks obtained from remote sensors allow, in the case of maintenance, to anticipate or to remain in control operations and thus to replace just what is necessary, or even, for a defective solution that should leave the market, to imagine the R4 to R9 strategies. These strategies show that Smart PSS are high added value solutions for different stakeholders: users, providers, the society, or politicians, regarding their injunctions to reduce waste, minimize the consumption of natural resources and reduce energy consumption.

Smart PSS can be a lever for environmental performance if they are designed considering the potential they represent and if the support infrastructures for their design, production, provision, use and end-of-life treatment exist and are rationalized. To help achieve this objective, several requirements derived from [7] need to be considered (Table1). As can be seen, the offer reconfigurability to adapt over time to the usage needs and to satisfy the customer in the long term is a common requirement to both the user and the provider of the solution.

Table 1. Stakeholder's requirements regarding a Smart PSS offering (derived from 7).

\begin{tabular}{|l|c|c|c|c|}
\hline \multicolumn{1}{|c|}{ requirement } & $\begin{array}{c}\text { customer } \\
\text { user }\end{array}$ & provider & society & politicians \\
\hline response to functional requirements & $\mathrm{X}$ & $\mathrm{X}$ & & \\
\hline quality of user experience & $\mathrm{X}$ & & & \\
\hline customised offering & $\mathrm{X}$ & & & \\
\hline reconfigurable offer & $\mathrm{X}$ & $\mathrm{X}$ & & \\
\hline market drivers & & $\mathrm{X}$ & $\mathrm{X}$ & \\
\hline economical dimension & $\mathrm{X}$ & $\mathrm{X}$ & $\mathrm{X}$ & $\mathrm{X}$ \\
\hline social dimension & $\mathrm{X}$ & $\mathrm{X}$ & $\mathrm{X}$ & $\mathrm{X}$ \\
\hline environemental dimension & $\mathrm{X}$ & $\mathrm{X}$ & $\mathrm{X}$ & $\mathrm{X}$ \\
\hline good compromise between cost, quality and time & $\mathrm{X}$ & $\mathrm{X}$ & & \\
\hline technological innovation & $\mathrm{X}$ & $\mathrm{X}$ & & \\
\hline e-service proposition & $\mathrm{X}$ & $\mathrm{X}$ & & \\
\hline safety and reliability & $\mathrm{X}$ & $\mathrm{X}$ & & \\
\hline
\end{tabular}

\subsection{From Smart PSS to Smart Reconfigurable PSS}

Reconfigurable systems have been around for a long time now. The well-known are Reconfigurable Manufacturing Systems (RMS), defined as being able to quickly change their structure, as well as their hardware and software components, to quickly 
adjust to new production needs. To do so, RMS are designed based on predefined equipment components that can be rearranged, moved and replaced quickly using the following principles: modularity, scalability, integrability, convertibility, reliability, maintainability and customization [13]. Considering the definition and typology of Smart PSS and the requirements set out in table 1, a Smart PSS can be viewed as a new type of reconfigurable system which must obey the same rules of rapid adaptation to needs, i.e. usage needs and not production needs. In any case, the adaptation must be quick and with the least effort. We thus propose to use modularity, key concept of RMS to design Smart and sustainable PSS [14].

Modularity concept has already been used to design PSS [15], [16]. Here we assume that the design of Smart PSS will be based on the composition of products and services functional units, assembled to obtain a sustainable composition, considering all the requirements above-mentioned. Smart PSS instrumentation allows to consider two different cases: one involved in the design of the initial solution and the other involved in the redesign or adjustment of this solution to the customer's usage needs over time.

In the first case, the choice of products, support services and additional services can be personalized and the whole can be instrumented according to the customer's needs, defined based on the desired uses and the accessible product support infrastructures.

In the second case, since usage information can be collected either through direct interaction with the customer or through direct feedback from sensors integrated into the initial offer, the system can be augmented or reduced in functionality. The use of modularity is, in this case, a key element to increase or decrease the functional scope of the physical part of the PSS and thus improve PSS sustainability as it allows to reach the highest level of the $10 \mathrm{R}$ strategies. Reconfigurability through modularity has an advantage for scalable solution design, able to meet users' needs over the long term, provided that the user can explicit his needs when designing the first offer. For this, we suggest a co-design user-provider of the offer.

\subsection{User-provider Smart Reconfigurable PSS Co-design}

A customized solution, co-designed by the user and the provider at the outset and adapted to changes in usage throughout the link between the solution and its user, ensures a high value-added solution for these two stakeholders. This is because the system is then adapted to the most demanding requirements and its unused components can be reused by the provider to meet the needs of other customers. This opportunity is part of the Corporate Social Responsibility (CSR) and on the way in which organisations make a PSS offer available to their clients, other objectives such as the search for quick profitability compromise the sustainability of the offers proposed. Several drawbacks emerge in this context: the needs to which the PSS respond are sometimes unclear, the scope of the related service system is poorly defined and the impact of the definition of the service system on its components poorly qualified and quantified. These facts generate problems of mismatch between specifications and needs, service delivered, and service wanted, cost and value, or services offered and uses of services, which negatively impact on the objectives of the companies. This is reinforced in a multi-organisational context because the difficulty is not only to propose a coherent offer, but also 
to analyse the compatibility of the processes and the logistical network supporting this offer throughout its life cycle, while guaranteeing the satisfaction of all its stakeholders. The co-design user-provider allows to have a customer centric approach recognised by several authors as allowing the delivery of higher service quality and enhancement of customer satisfaction [17].

Based on all the considerations presented in part 2, we propose in the next section the design challenges and principles on which we propose to build the three-dimensional framework for Smart reconfigurable PSS design.

\section{Design Challenges and Framework}

The design framework is based on the simultaneous engineering of product, process and supporting infrastructure. The product is here extended to Smart PSS. The requirements that drive this design are those presented in table 1. Interaction with the customer is heard throughout the design process, i.e., until the best compromise between all expectations is found. The processes here are the support processes for the design, manufacturing and implementation of the Smart PSS consisting of the product, the supporting and additional services, and the associated technologies. The supporting infrastructure is considered as being made up of all the partners constituting the supply chain required for the design, realization, provision, maintenance in operational conditions and treatment at the end of the product's life (Figure 2).

The principle of modularity consists in assuming the smart PSS as an arrangement of functional units of products and services. Therefore, as soon as the needs are expressed, an analysis of the functional units of the library formed by solution providers is carried out to see whether units are available. Three scenarios can occur:

- all the necessary units exist without a variant. An analysis then consists in simulating the coupling and comparing the solutions on the basis of criteria classically used in reconfigurability analysis (time, difficulty of coupling, etc.).

- all the necessary units are present with a variant, the analysis then consists of simulating the coupling and comparing the solutions on the basis of criteria classically used in reconfigurability analysis. Once the choice is done, a double analysis of process compatibility and support networks design can be carried out.

- some elements are missing and. In this case, either the requirements must be revised or a solution must be found through innovation.

In case there is no process compatibility or the support network design is not feasible; the offering must be modified (Figure 3). The metrics proposed to ensure the sustainability of the offer and stakeholders satisfaction, the tools as well as the methods allowing to perform the different sub activities contained in the three main ones are further detailed in [7]. It corresponds to the first case of the initial design of the offer but does not exclude other phases related to the redesign of adapted offers over time. Indeed, it will then be a question of analyzing the additional modules desired or those to be removed and of redesigning the adapted offer by checking the compatibility of the processes and supporting infrastructures as initially. Obviously, a digital twin of the 
PSS, processes and supporting infrastructures would be useful in carrying out tests, particularly about the complexity of coupling.

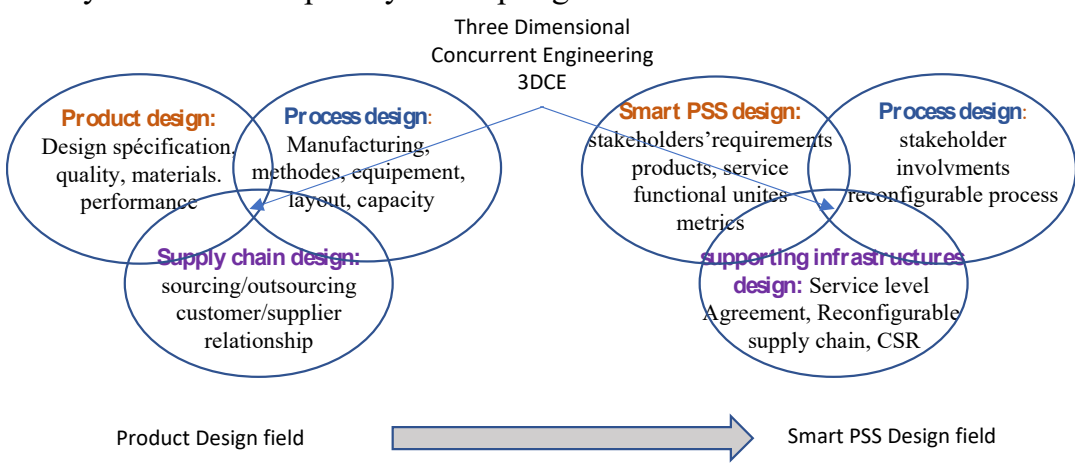

Fig. 2. 3DCE Smart reconfigurable PSS principles, adapted from (6).

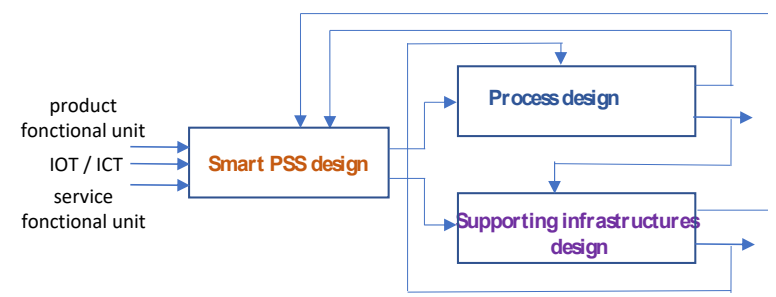

Fig. 3. 3DCE dynamic.

\section{$4 \quad$ Framework Implementation}

\subsection{Modeling Process Approaches and PSS}

In [18], the authors introduce the basic principle of a service delivery, that is an interaction within a service provider/consumer pair oriented from the provider to the consumer. The intensity of the service delivered grows in the same way as a parameter that characterizes the provider/consumer pair. A provider is identified by his function and is noted P. A consumer is characterized by his need. Of course, an object cannot be limited to being a provider or a consumer. Therefore, it is generally considered that objects can behave simultaneously as both. The initial principle presents an object as a single provider or consumer of services. Clearly, a complex object can provide and/or consume several services. Consequently, an object can be a provider/consumer of several services. The service provision relationships then become more complex, i.e., each relationship is defined for a given service. An object is then part of a series of services, linked to another object upstream as a service consumer and to an object downstream as a service provider. The authors proposed to call the "object" providing or demanding the service a "service agent" or, in short, a "sergeant". 


\subsection{Modeling of Behavior, Functions, and Data}

Indeed, the service modelling also requires the modelling of the interactions between multiple services; this process can lead very quickly to a significant level of complexity from a static point of view and even more in a dynamic view. proposed in previous works [19] a first tentative to represent service in simulation. We therefore focus in this paper on the establishing operations for a single service coupling in the G-DEVS formalism [20]. This discrete formalism is selected because of its formal property and its time management capability. We propose to model each service component through a G-DEVS model based on attributes. The model attributes are described from a qualitative and quantitative point of view and all elements (actors and material) that interact within its environment are required. New Smart PSS design and development is based on a strategic analysis whose objective is to define lines of innovation while keeping sustainability as core concern. Most of the time, innovations are incremental -series of small steps -as enterprises find ways to update their products and processes or to integrate basic services. Simulation principle is to analyze the possibility that new functionalities supplement a PSS existing one while receiving benefits, if any, of components already used to fill these existing functionalities. Specifically, the assembly of components can be simulated to measure their capacity to easily interact and to cope with the customers' need and use, with the manufacturers 'profit expectations and with the environmental incentive. The simulation of scenario tests can give clue to manufacturers to develop and set up a win-win strategy with their customers, and environment.

\subsection{Service Process and Service Process Value Model}

Service process is an important part of service as it is the operational workflow for service delivery. The execution of service processes is respecting an SLA between service provider and customer. The SLA specifies the requirements of the customer used to monitor and verify the contract. Under the SLA, the candidate service elements of each service can be divided into different service set, and the service process reaching customer's requirements can be constructed quickly. As described by Zhou in [21], for the same requirement of the customer, under different SLA constraints, the service provider can select different service elements to form different service processes.

According to Zhou [21], Service value is a common metric recognized by the stakeholders of a service, the service requester, and the service providers. System requirements of smart PSS toward customer needs and co-creative value propositions Several parties have to contribute to co-create value in a collaborative production to meet an overall value expectation [4]. However, in general, different PSS actors can have different PSS value expectations [5]. Therefore, value is multidimensional, and an actor's expectation of value may contain only some of these dimensions. Because of the different concerns, each person may define their values from different dimensions. For example, value can be defined from the economic point of view, ownership of the product, the economy of resources used and the customer experience, etc. Three dimensions were used to define service value: time and space, profit, and experience in [21]. The time and space dimension refers to the requirements of creating service value in time 
and space, which can only be achieved by meeting the requirements. Service value is strongly related to the activities in the service process. Time and space dimension reflects the time consumption and location/status changes in activities.

The profit dimension refers to the different benefits obtained by actors in the service activity, including economic benefits, physical products ownership, information obtained, etc. It is related to the service actors since each actor in the service process, including the customer, benefits from it.

The experience dimension refers to the intangible value or impact of service process or service results, including corporate reputation, social impact, customer satisfaction, experience, and skills, etc. Experience dimension is related to the effect of service process or result.

The sustainability dimension must be considered in the early design phase to reduce potential failure to meet the environmental and social requirements in delivery stage. However, according to [22], the existing PSS evaluation frameworks consider less about characteristics of digitalization and smartness.

In addition, in the design process of smart PSS [23], since the creation of value is inseparable from the use of smart resources, the resources need to be extended to smart objects, tools, materials, products, data, etc. The operationalization of the 3DCE framework in the context of Smart PSS consists in adding the process and value dimensions.

\section{Framework Operationalization}

\subsection{Smart PSS Value}

Smart PSS value includes the profit and usage dimensions that refer to the benefits obtained by actors in the service activity. Since Smart PSS, it adds the sustainability dimension [22] as a core global benefit since it reduces the environmental and social impact. Obviously, it is related to the service actors involved since each actor in the service process must contribute in a sustainable way and/or benefits from it.

Then, the experience dimension refers to the intangible value or impact of service process or service results, including corporate reputation, social impact, customer satisfaction, experience, and skills, etc. Experience dimension is related to the effect of service process or result. The PSS user experience dimension is increasingly important in the service and digital domain (in digital domain it is known as UX, i.e., User Experience). It corresponds to the way a service is perceived by its users or the customers. The user experience includes several criteria that are not yet extensively defined but literature up to now. It can include criteria such as ergonomics, usage, and satisfaction. In addition, in the process of PSS, the creation of value is inextricable from the use of resources. These resources can be human, materials, data, such as described in MDISE [24].

\subsection{Smart PSS Service Process}

In the proposed approach, a smart PSS is composed of different service elements coming either from a library (Figure 5 top left side), such as described in sergeant approach, 
which represent specific activities or tasks in the service process or service to be created on demand. Hence, each service process is composed of different activities organized in workflows (Figure 5 middle left side), which are executed by resources (Figure 5 bottom left side) to complete the whole service. In the service process described in Figure 5 right side, each activity needs to be fulfilled by at least one actor that can be human, including customer, service provider and participant and artefact or digital support form IT. By participating in the activities, resources (co-)create value, exchange value, and meet their own value expectations. Workflows are picked from library or created on demand according to the specification of customer needs.

\subsection{Smart PSS Process Value Model}

The user experience and sustainability are central element in mixing product and digital content in the building of Smart PSS process value. The goal is to create the most fluid and frugal pairing possible between the product, service, and user through a PSS and potentially a web-based data collection form IoT for smart PSS such as described in the figure 3 right side. The idea is, when pairing process, to limit the overlap between functionalities and resource used at the frontier of PSS subcomponents connection. A fluid connection of services and its smart support generates less consumption of resources and make much easier the smart PSS usage, reduces the impact on the environment and can increase loyalty of customer, as it is the case in buying and using physical products. In a chaotic e-service where it is almost impossible to find, produce and provide what the user is looking for or in slow PSS delivery; the potential customer will not be inclined to proceed to the PSS usage. On the contrary, in an ergonomic and aesthetic service delivery approach, the same customer will be much more likely to spend time there and to proceed to the act of service usage. The main causes of unpleasantness that spoil the user experience are usability issues that prevent from non-expert to use it, bugs that start over the service during run time, non-intuitive usage that slow down the access to the service, information not found that demotivate to reuse the service. Users who leave the e-service support frustrated are unlikely to try again on the same PSS, so they will naturally go to its competitors. Therefore, the contribution proposed will contribute to monitor the user experience on the service delivery process and applications and make it a central element of the PSS digital strategy.

\section{Conclusion and Future Works}

This paper presents a framework for Smart Reconfigurable PSS design that lays on several principles: the integration of multiple stakeholders' requirements to reach sustainability objectives, the co-design user/provider of the solution to increase satisfaction, the use of modularity to ensure user satisfaction over time, the use of IOT and eservice to get behavioral information on the user and update user' SLA, process and support infrastructure reconfiguration. A way to implement this framework is briefly presented. Future research aims at consolidating the framework and testing its implementation on real design cases. Another perspective is to define the digital twins of the 
process of creating the offer and the supporting infrastructure to be able to digitally test the design possibilities of a Smart Reconfigurable PSS.

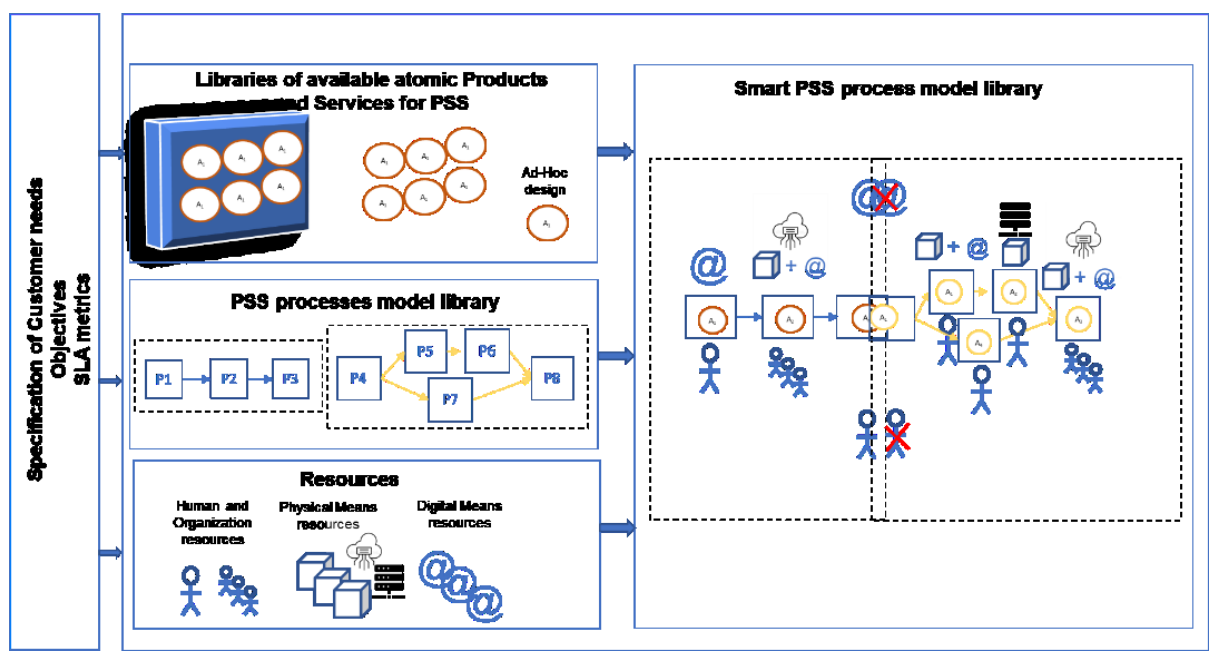

Fig. 4. Coupled approach mixing product and service for Smart PSS.

\section{References}

1. Goedkoop, M.J., Van Halen, C.J., Te Riele, H.R., Rommens, P.J.: Product service systems, ecological and economic basics. Report for Dutch Ministries of environment (VROM) and economic affairs (EZ). 36, 1-122 (1999).

2. Vuidel, P., Pasquelin, B., ADEME: Vers une économie de la fonctionnalité à haute valeur environnementale et sociale - Synthèse, (2017).

3. Potting, J., Hekkert, M.P., Worrell, E., Hanemaaijer, A.: Circular economy: measuring innovation in the product chain. PBL Publishers (2017).

4. Liu, Z., Ming, X., Qiu, S., Qu, Y., Zhang, X.: A framework with hybrid approach to analyse system requirements of smart PSS toward customer needs and co-creative value propositions. Computers \& Industrial Engineering. 139, 105776 (2020).

5. Li, X., Wang, Z., Chen, C.-H., Zheng, P.: A data-driven reversible framework for achieving Sustainable Smart product-service systems. Journal of Cleaner Production. 279, 123618 (2021).

6. Watanabe, K., Okuma, T., Takenaka, T.: Evolutionary design framework for Smart PSS: Service engineering approach. Advanced Engineering Informatics. 45, 101119 (2020).

7. Guan, H., Alix, T., Bourrieres, J.-P.: An Integrated Design Framework for Virtual Enterprise-Based Customer-Oriented Product-Service Systems. Procedia CIRP. 83, 198-203 (2019). https://doi.org/10.1016/j.procir.2019.03.143.

8. Coba, C.M., Boucher, X., Gonzalez-Feliu, J., Vuillaume, F., Gay, A.: Towards a risk-oriented Smart PSS Engineering framework. Procedia CIRP. 93, 753-758 (2020).

9. Tukker, A.: Eight types of product-service system: eight ways to sustainability? Experiences from SusProNet. Business strategy and the environment. 13, 246-260 (2004). 
10. Van Ostaeyen, J., Van Horenbeek, A., Pintelon, L., Duflou, J.R.: A refined typology of product-service systems based on functional hierarchy modeling. Journal of Cleaner Production. 51, 261-276 (2013).

11. Aas, T.H., Breunig, K.J., Hellström, M.M., Hydle, K.M.: Service-oriented business models in manufacturing in the digital era: toward a new taxonomy. International Journal of Innovation Management. 2040002 (2020).

12. Casati, F., Shan, M.C., Georgakopoulos, D.: Special issue on e-services. SPRINGERVERLAG 175 FIFTH AVE, NEW YORK, NY 10010 USA (2001).

13. Koren, Y., Gu, X., Guo, W.: Reconfigurable manufacturing systems: Principles, design, and future trends. Frontiers of Mechanical Engineering. 13, 121-136 (2018).

14. Sonego, M., Echeveste, M.E.S., Debarba, H.G.: The role of modularity in sustainable design: A systematic review. Journal of Cleaner Production. 176, 196-209 (2018).

15. P.P. Wang, X.G. Ming, D. Li, F.B. Kong, L. Wang, Z.Y. Wu, 2011: Modular Development of Product Service Systems. Concurrent Engineering. 19, 85-96 (2011). https://doi.org/10.1177/1063293X11403508.

16. Sun, J., Chai, N., Pi, G., Zhang, Z., Fan, B.: Modularization of product service system based on functional requirement. Procedia CIRP. 64, 301-305 (2017).

17. Hao GUAN: An integrated design framework for Customer-Oriented PSS based on ThreeDimensional Concurrent Engineering, (2019).

18. Alix, T., Zacharewicz, G., Vallespir, B.: Service Systems Modeling and Simulation: The Sergent Distributed Approach. In: Mertins, K., Bénaben, F., Poler, R., and Bourrières, J.-P. (eds.) Enterprise Interoperability VI. pp. 357-367. Springer International Publishing, Cham (2014). https://doi.org/10.1007/978-3-319-04948-9_30.

19. Alix, T., Zacharewicz, G.: Product-service systems scenarios simulation based on GDEVS/HLA: Generalized discrete event specification/high level architecture. Computers in Industry. 63, 370-378 (2012).

20. Zacharewicz, G.: Generalized Discrete Event System specification: A state-of-the-art study. SIMULATION. 0037549718777626 (2018).

21. Zhou, X., Zacharewicz, G., Chen, D., Chu, D.: A Method for Building Service Process Value Model Based on Process Mining. Applied Sciences. 10, 7311 (2020).

22. Liu, L., Song, W., Han, W.: How sustainable is smart PSS? An integrated evaluation approach based on rough BWM and TODIM. Advanced Engineering Informatics. 43, 101042 (2020).

23. Zheng, P., Xu, X., Trappey, A., Zhong, R.: Editorial Notes: Design innovation of Smart PSS. Advanced Engineering Informatics. (2020).

24. Zacharewicz, G., Daclin, N., Doumeingts, G., Haidar, H.: Model Driven Interoperability for System Engineering. Modelling. 1, 94-121 (2020). 